\title{
Implementing toxicity testing in the 21st century: challenges and opportunities
}

\author{
Paul A. Locke*
}

Department of Environmental Health, Johns Hopkins Bloomberg School of Public Health, 615 North Wolfe Street, Baltimore, Maryland 21205, USA

Email: plocke@jhu.edu

*Corresponding author

\section{Margit Westphal}

McLaughlin Centre for Population Health Risk Assessment, Institute of Population Health,

University of Ottawa,

1 Stewart St., Ottawa, Ontario, K1N 6N5, Canada

Email: Margit.Geisterfer@uottawa.ca

\section{Joyce Tischler}

Animal Legal Defense Fund,

170 E. Cotati Avenue,

Cotati, California 94931, USA

Email: jtischler@aldf.org

\section{Kathy Hessler and Pamela Frasch}

Center for Animal Law Studies, Lewis \& Clark Law School, 10015 SW Terwilliger Blvd., Portland, Oregon 97217, USA

Email: khessler@1clark.edu

Email: pfrasch@1clark.edu

\section{Bruce Myers}

Animals | Environment PLLC, 1875 Connecticut Avenue NW, 10th Floor, Washington, DC 20009, USA

Email: myers@aelaw.org 


\section{Daniel Krewski}

McLaughlin Centre for Population Health Risk Assessment, Institute of Population Health,

University of Ottawa, 850 Peter Morand, Ottawa, Ontario, K1G 3Z7, Canada

and

Department of Epidemiology and Community Medicine, Faculty of Medicine, University of Ottawa, 451 Smyth Road, Ottawa, Ontario, K1H 8M5, Canada and

Risk Sciences International,

55 Metcalfe Street, Suite 700, Ottawa, ON K1P 6L5, Canada

Email: dkrewski@uottawa.ca

Abstract: The publication of the US National Academy of Sciences report Toxicity Testing in the Twenty-First Century: A Vision and a Strategy (TT21C) has led to the development of new scientific techniques to modernise regulatory toxicity testing. From 2009 to 2010, a series of five international symposia were held to examine challenges, opportunities and policy issues associated with TT21C. Seven key themes emerged based on these meetings; that the TT21C vision and strategy: 1) is not self-implementing; 2) demands new toxicology techniques; 3) has a number of scientific knowledge gaps that need to be filled; 4) requires evaluation of the new tests to determine relevance, reliability, validity and regulatory acceptance by government agencies; 5) can be implemented under TSCA and the Federal Insecticide, Fungicide, and Rodenticide Act (FIFRA) as currently written; 6) requires multi-stakeholder input and commitment; 7) should harmonise acceptance of test data and methods on an international level.

Keywords: risk assessment; risk management; toxicity pathway; Toxic Substances Control Act; TSCA; environmental agents; REACH; EU Cosmetic act.

Reference to this paper should be made as follows: Locke, P.A., Westphal, M., Tischler, J., Hessler, K., Frasch, P., Myers, B. and Krewski, D. (2017) 'Implementing toxicity testing in the 21st century: challenges and opportunities', Int. J. Risk Assessment and Management, Vol. 20, Nos. 1/2/3, pp.198-225.

Biographical notes: Paul A. Locke is an Associate Professor at the Johns Hopkins Bloomberg School of Public Health in the Department of Environmental Health Sciences. He holds a joint appointment in the Department of Health Policy and Management. He is also a Distinguished Visiting Professor of Animal Law and Science at the Northwestern School of Law of Lewis \& Clark College. At Hopkins, he leads an integrated program that focuses on research-to-practice initiatives to better protect public health, especially in advancing evidence-based in vitro toxicology and radiation protection policy at federal and international organisations. He is admitted to practice law in the state of New York and the District of Columbia, the Southern District Court of New York and is a member of the bar of the United States Supreme Court. 
Margit Westphal is a Risk Analyst at the McLaughlin Centre for Population Health Risk Assessment at the University of Ottawa. Her academic background includes a PhD in Medical Sciences from the McMaster University, a Master's in Clinical Biochemistry from the University of Toronto, and a Master's certificate in Population Health Risk Assessment and Management from the University of Ottawa. Her current focus is on health risk issues related to chemical toxicity testing and prion diseases.

Joyce Tischler is the Co-Founder of the Animal Legal Defense Fund, and served as its Executive Director for 25 years. Currently, as ALDF's general counsel, she is responsible for in-house legal matters, as well as writing, lecturing on, and promoting the field of animal law. She has taught the fundamentals of animal law and created the first course in farmed animal law and policy. In 2009, The American Bar Association Tort Trial \& Insurance Practice Section (TIPS) Animal Law Committee honoured her with the Excellence in the Advancement of Animal Law Award. Her recent publications include 'Changing the dialogue about elephants', Quinnipiac L. Rev., Vol. 33, No. 485 (2015), 'The history of animal law, part II (1985-2011), Stan. J. Animal L. \& Pol'y, Vol. 5, No. 27 (2012), and 'The history of animal law, part I (1972-1987), Stan. J. Animal L. \& Pol'y, Vol. 1, No. 1 (2008).

Kathy Hessler is a Clinical Professor of Law and Director of the Animal Law Clinic at Lewis \& Clark Law School. She graduated with a J.D. from the Marshall-Wythe School of Law at the College of William and Mary and received her LLM from Georgetown University Law Center. Prior to teaching at Lewis \& Clark, she taught in clinical programs at Case Western Reserve University Law School, Cornell Law School, the University of Dayton Law School, the Capital University School of Law, and Georgetown University Law Center. She co-authored with Pamela Frasch among others of Animal Law in a Nutshell and has written numerous other law review and other articles, and she is co-authoring a new book on animal law. She writes and lectures primarily on animal law, animal legal education and clinical legal education.

Pamela Frasch is the Executive Director of the Center for Animal Law Studies (CALS) at Lewis \& Clark Law School. CALS is an academic animal law program with a focus on research, scholarship, and experiential education. In addition to her duties with CALS, she is a co-author of the casebook, Animal Law: Cases and Materials, now in its fifth edition and used in most animal law courses being taught in the USA. She is also a co-author with Professor Kathy Hessler among others of Animal Law in a Nutshell (second edition forthcoming 2016). She has taught survey and advanced courses in animal law since 1998, and has been recognised by the Humane Society of the United States and the Oregon Humane Society for her contributions to the field of animal law. Most recently, she became the inaugural recipient of the AALS Animal Law Section Award for Excellence in Animal Law.

Bruce Myers is an Environmental and Animal Lawyer based in Washington, DC. Previously, he was a Senior Attorney at the Environmental Law Institute (ELI), where he worked on the Institute's US and international programs. He launched ELI's Industrial Agriculture Law \& Policy Center. His domestic legal and policy research focused on water quality protection, the impacts and regulation of industrial agriculture, constitutional environmental law, the intersection of animal and environmental law, climate, and toxics regulation reform. He played a key role in the legal reform of Liberia's post-conflict nation's forest sector. He served as a Law Clerk to Senior Judge Edward Rafeedie of the US District Court for the Central District of California and is 
admitted to practice law in California and Washington, DC. He is an Adjunct Associate Professor at the American University Washington College of Law and a member of the IUCN Commission on Environmental Law.

Daniel Krewski is a Professor in the School of Epidemiology, Public Health and Preventive Medicine at the University of Ottawa, where he also serves as a Scientific Director of the McLaughlin Centre for Population Health Risk Assessment. His research interests include epidemiology, biostatistics, risk assessment, and risk management. He is a Fellow of the Society for Risk Analysis, the American Statistical Association, and a National Affiliate of the US National Academy of Sciences. He holds the Natural Sciences and Engineering Research Council of Canada Chair in Risk Science at the University of Ottawa.

This paper is a revised and expanded version of a paper entitled 'International implications of the U.S. National Research Council report on toxicity testing in the 21st century: challenges and opportunities in implementation' presented at Ottawa Symposium, Ottawa, Ontario, Canada, 29-30 June 2009.

\section{Introduction}

Approximately 84,000 chemicals are listed on US Environment Protection Agency (EPA) Toxic Substances Control Act (TSCA) inventory (USEPA, 2014b). The inventory is maintained by the USEPA under authority granted by TSCA. TSCA was enacted in 1976, and the TSCA inventory was first compiled in 1977. TSCA did not require toxicity testing for any of the chemicals that were in existence at the time the TSCA inventory was first compiled. 'New' chemicals - those added to the inventory after 1977 - require USEPA review before being used in commerce, but testing is not required for this review process. Today the number of chemicals that lack toxicity testing is very substantial and current animal intensive testing methods struggle to meet the present day demands as thousands of substances await health and environmental risk assessments. This toxics information gap exists worldwide under other chemical regulatory and legal regimes. The analysis of high-dose animal experiments with qualitative apical endpoints is lengthy, expensive, limited, and makes use of uncertainty factors to account for, among other things, animal to human extrapolations. To meet the needs of modern testing and fill the toxics information gap, a more practical approach to toxicity testing is needed (Hartung and Rovida, 2009; Hartung, 2009b).

The European Union (EU) and the USA have responded with different strategies to this enormous backlog of untested chemicals. The EU has enacted a comprehensive program called registration, evaluation, authorisation and restriction of chemical substances (REACH), with the overall mandate to promote better health, decrease environmental risks, and streamline, enhance, and promote innovation within the chemical industry. The onus of toxicity testing falls upon industry, importers, and downstream users to fill in knowledge gaps, replace highly toxic substances, and assure chemical safety. As of 21 January 2015 the REACH registration contains 8,162 unique substances and 40,791 dossiers (ECHA, 2015). REACH actively encourages the use of new in vitro methodologies and discourages the use of animals testing (European 
Commission, 2013; Schoeters, 2010). A recent 2014 report (ECHA, 2014) has commented that the use of in vitro testing with at least one endpoint has increased $20 \%$ in the REACH dossiers since 2011, and the use of read-across ${ }^{1}$ was used in $70 \%$ of the dossiers for at least one endpoint ( $\mathrm{ReFaC}, 2014)$.

The US Environmental Protection Agency (EPA addressed this problem in a systematic manner by first asking the US National Research Council (NRC) to review its current methods and suggest improvements. Two reports were published by the NRC's Committee, an interim report on toxicity testing for assessment of environmental agents in 2006 (NRC, 2006) and in 2007, a final report, 'Toxicity Testing in the 21st Century: a Vision and a Strategy' (NRC, 2007). The interim report provided a critique on the current methods used in toxicity testing as of 2006.

The final NRC report (published in 2007 and referred to in this article as TT21C) recommended a complete overhaul of the whole system. The overall goal of the new vision was to move toxicity testing towards a more evidence-based framework based on human toxicology, incorporating information from toxicity pathways. Decisions made regarding risks would be based on scientific facts that came from a solid foundation of understanding the signalling pathways involved in both homeostasis and disease, the chemical and molecular components involved in those reactions, the mechanism of action of the chemical or secondary metabolites, and the effect based on relevant acute, chronic or mixed doses from environmental sources. The predictive component of in silico modelling would play a major role in risk assessment with new types of default assumptions in place (NRC, 2007).

One of the main themes of TT21C was the alignment of critical perturbations of toxicity pathways with probable risk of human health effects. These toxicity pathways would symbolise normal biological signalling pathways that change as a result of chemical exposures. Chemicals would be screened quickly and effectively with a battery of high throughput, human cell-based in vitro assays, that would identify key perturbations of biological pathways and predict adverse health effects (NRC, 2007). Prioritisation of chemicals based on these in vitro formats would result in a tiered level of testing strategies with each subsequent step involving more sophisticated scientific methodologies such as 3D virtual-tissue and embryo modelling (Shah and Wambaugh, 2010; Cote et al., 2012). The TT21C vision and strategy thus incorporate both a screening and prioritisation step and integrated testing strategies. In this way, tests of greater complexity and presumably predictive value are reserved for later use and for those chemicals that have been identified as compounds of greatest concern (Krewski et al., 2014).

To accelerate progress in developing the methods and scientific knowledge called for by theTT21Cvision, a partnership was formed (Tox21) between:

1 the USEPA Office of Research and Development (ORD), National Center for Computational Toxicology (NCCT)

2 the US National Toxicology Program (NTP) headquartered at NIEHS

3 the National Chemical Genomics Center (NCGC) and National Institutes of Health (NIH) headquartered at the National Human Genome Research Institute (NHGRI)

4 the Food and Drug Administration (FDA). 
This partnership was memorialised in an interagency Memorandum of Understanding (MOU). A MOU was signed in 2010 (USEPA, 2010) to continue the research originally formulated in the strategic plan for evaluating the toxicity of chemicals (published in March 2009) (USEPA, 2009). The consortium and all the various programs are providing a systematic approach for the transition from in vivo to in vitro testing strategies (USEPA, 2014a).

TT21C is consistent with approaches taken, or advocated by, other organisations such as the Interagency Coordinating Committee for the Validation of Alternative Methods (ICCVAM) (National Toxicology Program, 2010), the Humane Society of the United States (HSUS), the European Center for the Validation of Alternative Methods (ECVAM), Center for Alternate Methods to Animal Testing (ZEBET), ALXR8 (partnership of Humane Society International (HSI), Flemish Institute for Technological Research, and the Free University of Berlin) and the Human Toxicology Project (partnership of corporations and non-governmental organisations). TT21C is also consistent with promotion of the 3R's;reducing, refining (decreasing or eliminating pain and distress), and/or replacing animal testing (Hartung, 2010; Seidle and Stephens, 2009; Stephens, 2010; The Humane Society of the United States et al., 2009; Liebsch et al., 2011).

The efforts associated with the TT21C report by US federal agencies demonstrate a seriousness of purpose regarding the development of the scientific techniques and methods that are needed for toxicity testing and addressing the toxics information gap. While that effort is a necessary first step toward report implementation, it is not, in itself, sufficient for achieving the TT21C vision and strategy. New scientific knowledge does not self-implement; in regulatory toxicology advances are catalysed by both new knowledge and changes in regulatory culture, policies and philosophy. To better understand how to make progress toward the implementation of the TT21C vision and strategy, and to examine challenges and opportunities and the range of policy issues associated with TT21C's adoption and use, a series of five international symposia were held.

From 2009 to 2010, these five symposia brought together international experts and participants in toxicology, risk assessment, industry and regulation to discuss changes needed in scientific risk assessment and regulatory policy to support theTT21C vision (Locke, 2009). This report summarises the major themes discussed at the five symposia and their major implications for TT21C implementation.

\section{Overview of the five symposia}

\subsection{First symposium: international implications of TT21C}

On 29 and 30 of June 2009, the University of Ottawa's McLaughlin Centre for Population Health Risk Assessment, in association with the Council of Canadian Academies and the Johns Hopkins Bloomberg School of Public Health, led a symposium in Ottawa, Ontario, Canada entitled The International Implications of the U.S. National Council's Report on Toxicity Testing in the 21st Century: Challenges and Opportunities in Implementation. The symposium examined the scientific, risk assessment and implementation challenges and opportunities generated by the TT21C report. It began by reviewing the toxicological evidence base for chemicals in both the US and EU member 
states. According to symposium speakers, of the more than 140,000 compounds consumed or used every day, we have reasonable toxicological information on only about 5,000 . This situation is not acceptable to the public in the US, Canada and in EU member states, and worldwide strategies are needed to fill this gap. Regulatory toxicology is only area in life sciences in which the same tests have been used for the past $40-50$ years. The vision and strategy set out in the TT21C report represents a point of departure (POD) for regulatory toxicology. The report charts a new approach, based on pathways of toxicity and high throughput testing. The USEPA and other federal agencies have been working on developing the methods and science to improve in vitro toxicology so it can be used in regulatory decision making. USEPA's ToxCast program and NIH's robotics laboratory are leading this effort. The initial USEPA library of 2800 compounds will be expanded to 10,000 , which will include 3,000 potential drug compounds that failed as candidates for development. In addition, USEPA is seeking to identify and test more than $100+$ assays that assess toxicity pathways involved in human disease and critical homeostatic functions. While many scientific uncertainties remain, this work is progressing rapidly.

In Canada, legislation has recently been enacted that focuses on the mode of action (MOA) for regulatory decision making. (It is possible that MOA and the pathways analysis (from TT21C) are very similar, but neither term is clearly defined.) This new legislation is forcing a reassessment of regulatory strategies. It seems clear that certain tools, such as quantitative structure activity relationship (QSAR) modelling, can be very useful in screening and prioritising long lists of potentially hazardous chemicals. Certain other chemical characteristics such as bioaccumulative ability and potential for exposure can be used for risk profiling. While not every chemical can be fully assessed using these and similar tools, risk can still be effectively managed if MOA is better understood, and MOA can be used along with default assumptions to make public health protective decisions. It is also recognised that certain regulatory programs are 'data rich' (i.e., possess considerable amounts of animal toxicology and sometimes human epidemiology data) and others are 'data poor'. As more and more in vitro toxicology data is collected, it will be necessary to compare the animal toxicology and human epidemiology data to in vitro toxicology data to evaluate similarities and differences, and determine how these varied data sources can be used together to protect human health and the environment.

The TT21C vision and strategy also raises questions and challenges for the risk assessment process. Risk assessment is at a cross-roads; its value to decision making is being questioned. The length and breadth of risk documents, and their utility for assisting in decision making, are under scrutiny. Adding in an assessment of the value of the risk information and an appraisal of risk data and it potential influence on decision making could help restore credibility. It is possible that the new methods developed pursuant to the implementation of the TT21C report could assist in strengthening risk assessment, especially if the data about toxicity pathways allows for the creation of some 'stopping points' for risk analyses and a way to organise the health hazards of compounds.

The vision and strategy set out in the TT21C report come to USEPA at a time when the agency is faced with the need to evaluate many chemicals, finite resources, limited time, and increasingly complex science. The agency is thus in great need of a better chemical risk management paradigm. A very logical first step in implementation of the TT21C report is to focus on those chemicals that are most likely to present a risk, based on the analysis of the type of mechanistic data that will be available from these new in vitro tests. This change in focus can be accomplished without a change in law, and would require greater reliance on mechanistic techniques and less use of animal toxicology. It is 
possible that an international body, such as the Organization for Economic Cooperation and Development (OECD), could be a vehicle through which mechanistic information is employed.

It is important to determine whether changes in regulatory practices will be needed to implement the TT21C vision and strategy. The existing toxicity testing system has a high cost - about $\$ 400,000$ for a full battery of animal tests. As a result, complete testing (via animal-based toxicology) is impractical. At present, substantial attention is being paid to the use of in vitro and in silico toxicology methods for screening and prioritisation. While these are logical first steps, it is important to recognise that regulatory agencies have the flexibility to use these tests for more complex decision making, too. Continuous evolution and improvement will be necessary so that these methods are up to the task. Without vigilance in this area, these new methods will be used solely for screening and not mature in a way that is consistent with the TT21C vision and strategy. Public participation and engagement can also be important factors in accelerating, shaping, and encouraging acceptance of TT21C implementation. Recalling the purpose of TSCA, - to protect human health and the environment - the benefits of increasing transparency and citizen involvement become clearer. First, consumer demand for greater toxicological information has driven the move toward TT21C as a way to close the toxics information gap. The public must be brought into to the TT21C implementation process so it can see how its demands are being addressed. Second, the paradigm shift anticipated by the TT21C vision and strategy - away from apical endpoints to pathways of toxicity, and toward mechanistic toxicology technologies centred around human cell lines - will mean that members of the public will be exposed to new and unfamiliar toxicology methods and information. It is important that citizens understand how regulators can use such information to make public health protective decisions. Third, public pressure and consumer demand can stimulate greater accountability and, perhaps, more trust and confidence in the system that regulates chemicals in commerce. Finally, the open data philosophy of ToxCast creates broader access to basic data compared to traditional evaluative programs. It seems logical that USEPA and other agencies should also share methodologies for assessment, and that members of the public and public interest groups will conduct analyses based on this data.

There are possible legal challenges, as well as opportunities, that could arise as the TT21C vision and strategy is being implemented in the US Agencies as well as industry should anticipate whether legal actions could be brought alleging that these 'new' testing regimes are somehow deficient or not appropriate. While the legislative history, and plain language, of TSCA do not require animal testing, moving away from the current paradigm of animal toxicology will likely require agencies to communicate about the benefits of this paradigm shift. In addition, at the present time the US Congress is considering bills that would substantially amend TSCA, and advocates of implementation of the TT21C vision and strategy should be vigilant in reviewing these bills with an eye toward whether suggested legislative changes are consistent with TT21C. Once implemented - assuming that TSCA amendments, if any, are not prohibitive - the TT21C testing paradigm has the potential to streamline regulatory decisions and accelerate progress toward eliminating the toxics information gap. It is also important to keep in mind a key question about the implementation of the TT21C report: how can this new system of toxicity testing be made more effective than the one it replaces? Without a clear answer to this inquiry, advocating for change will be much more difficult. 


\subsection{Second symposium: science, ethics and law of animal testing}

On 12 September 2009, the Center for Animal Law Studies at Lewis \& Clark Law School co-sponsored the second symposium, entitled The Science, Ethics, and Law of Animal Testing in the 21st Century: Are We on the Verge of a Paradigm Shift? This symposium, held in Portland, Oregon, explored the statutory and regulatory hurdles that must be addressed to fully implement the TT21C strategy and vision. Because this symposium was targeted at lawyers and law students, it began with a thorough introduction to regulatory science, covering the underlying concepts of the TT21C strategy and vision, an explanation of in vitro testing and in vivo testing, the nature of toxicity testing and toxicity endpoints, and how the 3 Rs and humane science are interrelated.

The legal and regulatory landscape of toxicity testing was also explored in great depth. The TSCA, the Federal Insecticide Fungicide and Rodenticide Act (FIFRA), and the Federal Food, Drug and Cosmetics Act (FFDCA) and the ICCVAM law all impact the implementation of the TT21C vision. TSCA and FIFRA can require testing, and are prime candidates for the paradigm shift contemplated by the TT21C report. The TSCA 'toxics information gap' has been well documented - the TSCA inventory contains over 80,000 compounds, and a full toxicological profile is available for very few. Implementation of the TT21C vision and strategy has the potential to bridge this gap over time. While FIFRA is a data rich program, the in vitro and in silico science being developed to implement the TT21C vision could also be very useful in FIFRA regulatory decision making. The ICCVAM law, which covers validation and regulatory acceptance, is problematic and has the potential to impede TT21C implementation. The law does not provide a clear path forward for validation and lacks flexibility. Once validated, regulatory acceptance by federal agencies is required under the law but there are many, many exceptions to the mandatory acceptance requirement. These exceptions reduce the probability of regulatory acceptance and weaken the incentive for proponents of in vitro testing methods to undergo ICCVAM validation.

Nevertheless, neither TSCA nor FIFRA prohibits the use of in vitro testing for decision making. In terms of implementation of the TT21C vision and strategy, changes in these laws are not required. Regulatory changes could be necessary, especially in cases where a required test or battery of tests demands the use of outdated and outmoded methods. The ICCVAM law would likely benefit from amendment. When greater acknowledgement exists that validation can be accomplished outside of the ICCVAM process, prospects for in vitro regulatory toxicology will improve greatly.

It is important to point out that, in the past, the issue of moving away from animal toxicology in toxicity testing was solely seen by many policy makers as an animal welfare issue. More specifically, the arguments against animal testing were based on ethical concepts against using animals and increasing welfare protections. TT21C has changed and enhanced that dialogue by establishing in vitro and in silico science as the best science to use for regulatory decision making purposes. Thus advocacy to reduce the use of animals is now based on both ethics and good science. As a result, it will be important to create new coalitions of advocates that encompass both scientific and welfarist approaches. 


\subsection{Third symposium: making the business case for alternatives}

On 5 November 2009, the University of Chicago School of Law and Animal Legal Defense Fund sponsored the third symposium, entitled Implementation of the US National Research Council report on Toxicity Testing in the 21st Century: Can We Make the Business Case for Alternatives? The symposium focused on what the report means from the perspective of business leaders in the US. The business community is often required by law to conduct toxicity testing. The costs of both the current and new testing approaches, as well as the expenses involved in switching from one to the other, were examined, along with the potential for products liability and the appropriate role of the business community in implementing the TT21C vision and strategy.

The symposium speakers generally agreed that in the long term the toxicity testing strategy and vision set out in the TT21C report would be cost-effective. In addition, the emphasis on human models has the potential to produce more relevant and accurate data and, by extension, potentially more public health protective decision making. Furthermore, the implementation of the TT21C strategy and vision is consistent with models of corporate citizenship that stress sustainability, consumer protection and regard for animal welfare, and the $3 \mathrm{Rs}$ principles.

Several challenges face the business community. First, the multinational nature of the cosmetics, pharmaceutical and chemicals businesses means that standards that vary across jurisdictions create product formulation and marketing challenges. For example, in the cosmetics industry after March 2013 no EU member state has allowed the marketing of any cosmetic products if the product or any component is tested on animals. In contrast, other national laws require animal testing. As a result, cosmetics companies must develop two separate product lines to comply with these conflicting laws. Second, using newer toxicity testing methods can be a challenge for regulatory acceptance. At present, under TSCA there are few clear ground rules regarding what testing data is acceptable for decision making. This situation creates disincentives for developing in vitro and in silico methods. More specifically, from a business standpoint the development and use of newer in vitro methods will be hampered if agencies will not accept the data they generate. Third, it is possible that applying newer tests could raise product liability issues. However, if these tests are validated and their data is accepted by regulatory agencies, product liability concerns should be greatly diminished.

The report's implementation creates opportunities too. It is important to remember that the TT21C vision and strategy will act as a technology forcing mechanism, and that companies in the business of developing in vitro testing methods could benefit because of the incentives created by the report. Companies that are currently involved in animal-based testing could also see that a business advantage might be gained by expanding their product line to include non-animal tests. In addition, the emphasis on human cell line testing and high throughput methods could spur new insights into the molecular and cellular mechanisms. Finally, those companies that market products requiring testing could benefit from a faster track testing process that gets products to market more quickly. 


\subsection{Fourth symposium: creating a roadmap to implementation of TT21C}

On 21 June 2010, the Environmental Law Institute, an international, not for profit, research and training organisation collaborated with the Johns Hopkins Bloomberg School of Public Health to host the fourth symposium, entitled The Future of Chemical Toxicity Testing in the United States: Creating a Roadmap to Implement the National Research Council's Vision and Strategy. The symposium covered:

1 the status of implementation of the vision for chemical toxicity testing three years after the TT21C report was issued

2 what the federal agencies are doing - and planning to do - to ensure implementation of the TT21C vision

3 stakeholder perspectives on implementation across a range of viewpoints: industry, public health and environmental protection, the academy, and animal welfare

4 where implementation of the TT21C vision fits into a landscape of potentially broad legislative reform for toxic substances, harmonization with Canadian requirements, and scarcity of financial resources.

The symposium featured speakers from US regulatory agencies and experts from the private sector and academia. USEPA's Assistant Administrator for Chemical Safety and Pollution Prevention opened the symposium by reaffirming USEPA's commitment to its chemicals testing program and implementation of the vision and strategy in the TT21C report. After a description and discussion of the TT21C vision, the symposium turned to the challenges to implementing the TT21C report goals and opportunities for its advancement. It was noted that USEPA and several other federal agencies have entered into a MOU regarding the report, and that leadership at each agency has reaffirmed commitment to the TT21C vision and strategy. Challenges involve both the need for new scientific methods that are cell-based and high throughput, as well as the validation and regulatory acceptance of these tests. There is reason to be optimistic with respect to methodological development; technology is evolving rapidly.

Federal agency representatives echoed the themes of advancing technology and federal agency cooperation. New in vitro and in silico science at NIH and USEPA is evolving rapidly through both the Toxcast program and Tox 21 . Tox 21 is an interagency program that is using robotics to screen and prioritise thousands of chemicals that need toxicity testing. The Toxcast program uses automated high-throughput screening assays to expose cells or proteins to chemicals, which are then screened for changes that could suggest toxic effects. These innovative methods have the potential to limit the number of required laboratory animal-based toxicity tests while quickly and efficiently screening large numbers of chemicals. At $\mathrm{NIH}$, the Chemical Genomics program is advancing methods in high-throughput screening, cheminformatics and chemistry with an emphasis on genomics and chemical interactions.

As these new tools and technologies are being developed, validated and used, it is critical to establish how they can be utilised to make regulatory decisions by agencies such as USEPA and FDA. It is important to highlight that the TT21C vision is not self-implementing. Clearly, federal governmental and private sector resources will be crucial in advancing the science, and regulatory agencies need to find ways to use the data created by these new techniques. Also, it is apparent that progress toward 
implementation is likely to be nonlinear. The creation of a new body of science is a large undertaking, and scientific progress cannot be charted or predicted. We should not expect that the implementation process will travel along a straight and narrow path. Third, implementation will move forward no matter what the legal picture looks like. Whether the current version of TSCA remains untouched or new legislation is enacted, the shift in toxicity testing will take place. A new legal regime, if put into place, should incorporate our new understanding of toxicity testing and provide flexibility for it to grow. However, even without change, the present system can accommodate the TT21C vision and strategy.

Drawing on advances across a range of disciplines - such as genomics, bioinformatics, systems biology, and computational toxicology - the NRC set out a new paradigm for chemical testing that it believes is not only more predictive of adverse effects in humans, but also faster and less expensive than current models, and less dependent on whole-animal-based testing methodologies. This paradigm transformation requires a long term commitment: the TT21C committee recognised that implementation of its recommendations would require substantial resources, as well as the involvement of multiple organisations in government, academia, industry, and the public, and could take a decade or two to achieve.

\subsection{Fifth symposium: an EU perspective on the way forward}

On 22 June 2010, The American Consortium on European Union Studies (ACES) sponsored the fifth symposium, entitled Implementing the U.S. NAS Toxicity Testing Report: An EU Perspective on the Way Forward. The symposium was held in Washington, DC and featured speakers from the University of Konstanz, OECD, COLIPA (the European Cosmetics Association), the EU Delegation of the European Union, and the Council of Canadian Academies.

Although the TT21C report is intended solely to provide recommendations for the USEPA's toxicity testing program, because of the multi-national nature of business and scientific research, the report's ramifications and implementation extend beyond US borders. In addition, current initiatives underway in the EU member states including REACH and developments in Canada overlap the approach set out in the TT21C vision and strategy. Finally, international efforts at harmonisation in testing and regulation are ongoing and must incorporate and account for trans-Atlantic differences.

The symposium began by examining the role of academia in developing regulatory testing strategies. The current focus is on one-to-one replacement of toxicological endpoints, separation among fields of expertise (e.g., drugs, pesticides, chemical and cosmetics) and a limited mechanistic emphasis. Under the present paradigm, chemicals are first tested in animals and limited cellular and pathway information is then sought. However, the TT21C vision and strategy calls first for the collection and evaluation of pathway-type of data. The 3Rs - refinement, reduction and replacement - could be useful to transition between the current and new paradigms.

The academic community has a multi-faceted role in advancing toxicity testing, in part by championing the 3 Rs through a testing approach that uses in-vitro and in-silico data. In vitro and in silico methods fall squarely in the 'replacement' arm of the 3Rs. Funding from the EU has assisted in bringing academic scientists to develop these replacement techniques, and collaboration with the business community has been useful in developing alternatives and applying them to decision making. A portion of EU 
funding has been targeted to replacement alternatives and an emphasis has been placed on high throughput tests.

Two examples illustrate this point. First, a human blood in-vitro pyrogen test to replace an in vivo rabbit test was developed in an academic environment. The in vitro pyrogen test relies on human blood incubation and an ELISA (enzyme-linked immunosorbent assay) read out to obtain results that can be applied to decision making in a way that minimises the need for, and might even eliminate, the in vivo rabbit test. Cell-based tests for developmental neurotoxicity are also being improved and show promise. These tests are built around the concepts of 'windows of sensitivity' in which different cell populations have different pathway responses and patterning markers.

OECD is a multi-national organisation that promotes policies designed to improve the economic and social wellbeing of people around the world. OECD contains 30 member nations, including the USA, and it has established a framework to share experiences, identify best practices, and coordinate the development and implementation of national and international regulations including testing guidelines. OECD is developing in vitro approaches for endocrine disruptor screening and is also applying QSAR tools to its testing protocols. It is working toward test methods that are organised around critical molecular events.

Although OECD is not involved directly in implementing the NAS vision and strategy, it is a leader in international harmonisation and home to a testing guidelines program. OECD's Directorate of the Environment houses this program in its environment, health and safety division. In recent years, the program has focused on hazard assessment toxicity factors, systems biology approaches to toxicity testing and non-animal methods.

Test guidelines adoption is accomplished by consensus, which can be a time consuming process. However, once adopted the program is legally binding on OECD member countries. It is estimated to have saved thousands of animals and $\$ 50$ to 60 million Euros per year by reducing duplication through mutual data acceptance and good laboratory practice.

In the EU, the business community is very involved in advancing alternative test strategies that do not use animals. This effort is especially important to the cosmetics industry. Activities within the cosmetics industry and its trade group, COLIPA (the European Cosmetics Association) provide an example of the role that the business community can play. The EU Cosmetics regulation, which enacted a marketing ban on cosmetics and cosmetics components that are tested on animals, is a major driving force in focusing activities. The regulation provided that by March 2013, all animal testing on cosmetics and their components are banned. The implementation of this directive has spurred the development of alternative non-animal tests. However, it also creates challenges for the business community, including the potential to slow or stop innovation. This is particularly true concerning some of the 2013 deadlines, for which non-animal toxicity tests are not available. Among the scientific hurdles that must be addressed are:

1 validation of new alternative testing methods

2 the recognition that a single in vitro assay cannot substitute for a toxicological understanding for whole organism toxicology

3 mechanisms of toxicological effects are not always understood. 
COLIPA is attempting to fill these scientific gaps through its ambitious research program. From 2007 to 2014, this program was expected to fund over 37 M Euro in research activities. To date, the COLIPA program has led to the validation of 11 methods for four endpoints, development of in-vitro methods for percutaneous penetration, which has been accepted by OECD, and pre-validation efforts for three skin allergy methods.

The Council of Canadian Academies pesticide management study is examining how non-animal toxicology can be used in evaluating pesticide toxicity and, like the TT21C report, provides an example of how public policy initiatives impact science and technology and, obversely, how science and technology can be used to influence new directions in policy. The process by which scientific innovations and public policy interact is not always transparent and can therefore be difficult to understand. There are parallels in other areas that might be useful for understanding this process. Three key messages have emerged from the pesticide management study. First, international collaboration is critically important. This collaboration starts with an agreement and discussion about overarching public policy principles such as the role of the precautionary principle and prior informed consent. Collaboration efforts will be most successful when discussions are focused on the fullest possible implementation of the new vision and strategy. Second, it is important to develop an interdisciplinary implementation process and plan. Although it is often discussed, it is hard to accomplish in practice. Transformative paradigms such as the TT21C vision and strategy incorporate diverse disciplines that include different and sometimes conflicting systems and beliefs. Third, it is essential to engage citizens and recognise the ethical and social ramifications involved in any paradigm change. Public policy decisions cannot be based solely on the best technical approach, because ultimately it is up to society to determine which risks to accept and how they will be incorporated into societal decisions. In order to obtain the social license to operate, a robust program of public involvement and input should be put into place early and used to obtain frequent input and feedback. A key question is how to design a science and technology 'contract' with citizens that will allow for implementation of the TT21C vision and strategy.

Both the EU and US are moving towards developing a system of in vitro and in silico toxicological tests to evaluate chemicals. One way to understand the difference in approach between the US and EU is to recognise that there are contrasting ways of achieving the same goals. The US is modernising its toxicity testing program using a 'top down' approach. It originates with its federal agencies and national scientific bodies, which have laid out a vision and strategy for change and implementation plans. In the EU, a 'bottom up' strategy is being implemented, based on grass roots support for broader use of non-animal alternative methods and funding of academic research and industry laboratories to develop the techniques needed to reach the goals of modernised toxicology. In other words, federal and wider European efforts are driven by the academic and business communities and public pressure. 


\section{Implementing the TT21C vision and strategy: opportunities and challenges}

The discussions and expert opinions offered at these five symposia illustrate three broad areas that present both opportunities and challenges to the implementation of the TT21C vision and strategy. These three areas - infrastructure for the development of new methodologies, application of these methodologies to regulatory decision making, and international harmonisation and stakeholder involvement, are examined in this section.

\subsection{Infrastructure for methods development}

One very clear message from the TT21C report, which was amplified by these five symposia, is that new, in vitro and in silico toxicological techniques are needed. The report clarifies that in moving toward what it classifies as 'option IV' reliable and validated methods are crucial (Table 1). The TT21C vision and strategy thus creates opportunities to advance the science of toxicology and the practice and art of risk assessment because it requires the development and application of new scientific testing methods. The thrust of these methods will be:

1 molecular (human cell lines)

2 pathway oriented

3 higher throughput.

Table 1 Four-phase approach to change from in vivo to in vitro models

\begin{tabular}{|c|c|c|c|}
\hline $\begin{array}{l}\text { Option I } \\
\text { In vivo }\end{array}$ & $\begin{array}{c}\text { Option II } \\
\text { Tiered in vivo }\end{array}$ & $\begin{array}{c}\text { Option III } \\
\text { In vitro and in vivo }\end{array}$ & $\begin{array}{l}\text { Option IV } \\
\text { In vitro }\end{array}$ \\
\hline Animal biology & Animal biology & $\begin{array}{c}\text { Primarily human } \\
\text { biology }\end{array}$ & $\begin{array}{c}\text { Primarily human } \\
\text { biology }\end{array}$ \\
\hline High doses & High doses & Broad range of doses & Broad range of doses \\
\hline Low throughput & Improved throughput & $\begin{array}{l}\text { High and medium } \\
\text { throughput }\end{array}$ & High throughput \\
\hline Expensive & Less expensive & Less expensive & Less expensive \\
\hline Time-consuming & Less time-consuming & Less time-consuming & Less time-consuming \\
\hline $\begin{array}{l}\text { Use of relatively } \\
\text { large numbers of } \\
\text { animals }\end{array}$ & Use of fewer animals & $\begin{array}{l}\text { Use of substantially } \\
\text { fewer animals }\end{array}$ & $\begin{array}{l}\text { Use of virtually } \\
\text { no animals }\end{array}$ \\
\hline \multirow[t]{2}{*}{$\begin{array}{l}\text { Based on apical } \\
\text { end points }\end{array}$} & $\begin{array}{l}\text { Based on apical } \\
\text { end points }\end{array}$ & $\begin{array}{c}\text { Based on perturbations } \\
\text { of critical cellular } \\
\text { responses }\end{array}$ & $\begin{array}{c}\text { Based on perturbations } \\
\text { of critical cellular } \\
\text { responses }\end{array}$ \\
\hline & $\begin{array}{l}\text { Some screening using } \\
\text { computational and in } \\
\text { vitro approaches; more } \\
\text { flexibility than current } \\
\text { methods }\end{array}$ & $\begin{array}{c}\text { Screening using } \\
\text { computational } \\
\text { approaches possible; } \\
\text { limited animal studies } \\
\text { that focus on } \\
\text { mechanism and } \\
\text { metabolism }\end{array}$ & $\begin{array}{l}\text { Screening using } \\
\text { computational } \\
\text { approaches }\end{array}$ \\
\hline
\end{tabular}


Using the information produced by these methods presents challenges for regulatory decision making. First, the nature of the data will be different from the data that is currently used in the regulatory system. In moving toward a system that, as described by the TT21C report, uses virtually no animals (see option IV, Table 1), it will be essential to encourage scientific dialogue to bridge the gap between the current data used in decision making (largely whole animal toxicology) and the new human cell-based data, particularly for risk assessments. The TT21C vision proposed a program timeline that overlapped four phases of important scientific advancements in assay development (see Table 1). The focus of these four phases is the elucidation, detection methods, and validation of toxicity pathways used in medium- and high-throughput screening assays. This phased-in approach allows past in vivo knowledge and new in vitro techniques to be compared and support one another and continue the risk assessment of chemicals. The new roadmap as discussed in the USEPA Strategic Plan integrates the three main components: "chemical screening and prioritization, toxicity-based pathways risk assessment, and institutional transition" (USEPA, 2009).

Risk characterisation will change from a single chemical-single outcome paradigm to a multi-chemical, multi-faceted analysis. Cumulative risk assessments will become the new standard of risk characterisation and categories of chemicals will be assessed together. Chemicals group analysis will be based on a system biology approach and default assumptions would integrate the complex interactions of multiple perturbation pathways. Cumulative risk assessment will likely evaluate competitive, additive and synergistic relationships based the effect the group of chemicals have on a network of interactions rather than that of a single toxicity pathway (Boobis et al., 2008; Zhang et al., 2010).

Additional attention should be paid to this incremental 'data integration' challenge. Important fundamental questions remain. For example, do we replace one part of the current system at a time or do we develop a whole new system and displace our old methodologies in one step? Second, it is important to acknowledge that these new methodologies will not create a 'one-for-one' substitution for existing tests. Using the new data will require that we create equivalent series of in vitro tests that can substitute for the animal-based toxicology. In other words, we need to make a conceptual shift from a system that relies on single animal toxicological tests and apical endpoints (i.e., a test for carcinogenicity) to a system of integrated, smaller step non-animal tests that evaluate molecular and cellular changes (i.e., tests that are predictive because they establish a series of critical genetic changes in cells that cannot be reversed, and take a system out of homeostasis).

\subsection{Application of new methods in regulatory decision making}

An additional set of opportunities and challenges involves the application of newly developed testing methods to regulatory decision making. Elegant laboratory technology must be valuable to decision makers; tests that 'work' in the lab must have a practical application in the regulatory environment. Applying these new methods within the current risk assessment framework creates opportunities to sharpen risk management, which has been evolving for the past 30 years (NRC, 1983, 1996, 2006, 2007). As the new methods of toxicity testing develop over the next 20 years, the validation process should also be in place to formalise these methods and synthesise a validation framework that would incorporate new and better methods as the scientific tools and techniques 
evolve. If regulatory methodology remains static as it has in the past, then every 20 years the whole system will again be out-of-date and the cycle of incorporating new and better testing methodologies would have to begin again.

Figure 1 Next generation framework for risk science

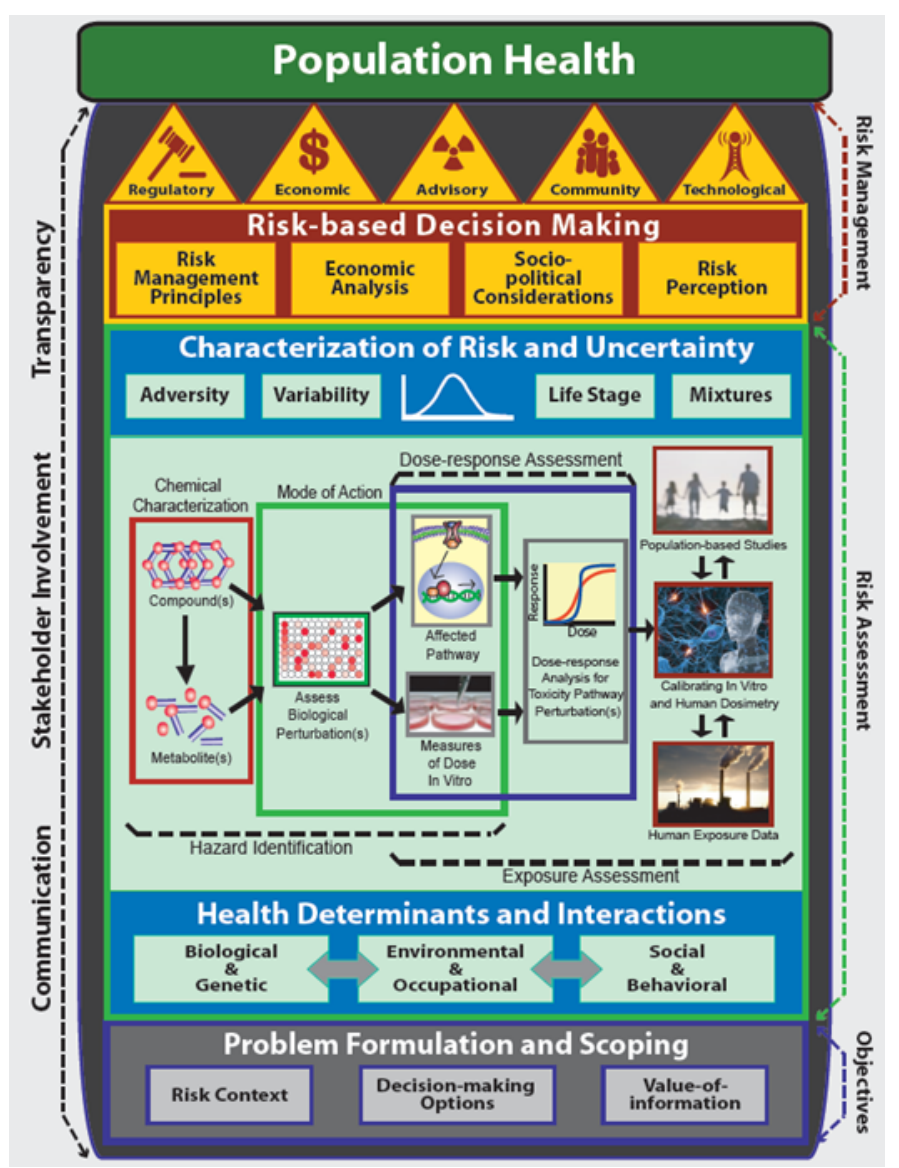

Notes: This framework is divided into three phases. 1) objectives: problem formulation and scoping takes into consideration risk context, decision making options and value-of-information. 2) risk assessment involves three sub-categories: (a) health determinants and interactions: adopt a population health approach that takes into account multiple health determinants that interact with risk factor(s) such as biology and genetics, environmental and occupational, as well as behavioural and social determinants of health. (b) new scientific tools and technologies: based on structure-activity relationships, high-throughput screening assays, stem cell biology, functional genomics, systems biology, computational systems biology, bioinformatics, biomarkers, pharmacokinetic models and adversity, and molecular and genetic epidemiology. (c) new risk assessment methodologies: new formulas and uncertainty factors for calculating exposure guidelines. 3) risk management involves two categories: (a) risk-based decision making that involves risk management principles, economic analysis, socio-political consideration and risk perception (b) risk management interventions with five possible categories, regulatory, economic, advisory, community, and technique.

Source: Krewski et al., 2014) 
The risk assessment process was first conceived in a 1983 NRC report Risk Assessment in the Federal Government: Managing the Process. This report, often referred to as the 'red book', was the first in a series of NAS committees and NRC reports on the risk assessment and risk management process. The standard four stages of the Red Book remain unchanged, but the scientific assessment conducted within each stage will change dramatically (NRC, 1983). Many of these changes were originally outlined in Chapter 4 of the TT21C report, and have subsequently been updated in recent publications by Andersen et al. (2010) and Krewski et al. (2011). Figure 1 illustrates the risk characterisation process where the four stages of risk assessment overlap with new scientific tools and technologies (Andersen et al., 2010; Krewski et al., 2011).

The red book was written at a time when animal-based toxicology was the primary means of obtaining data for risk assessment. A recent publication by one of the coauthors of this paper (Krewski et al., 2014) amalgamates three previous risk frameworks to bring together:

1 the TT21C report framework (NRC, 2007)

2 the framework established by the McLaughlin Center for Population Health (Krewski et al., 2007)

3 the NRC's 2009 risk and decisions report framework (NRC, 2009) (Figure 2).

Figure 2 A framework for risk-based decision-making that maximises the utility of risk assessment

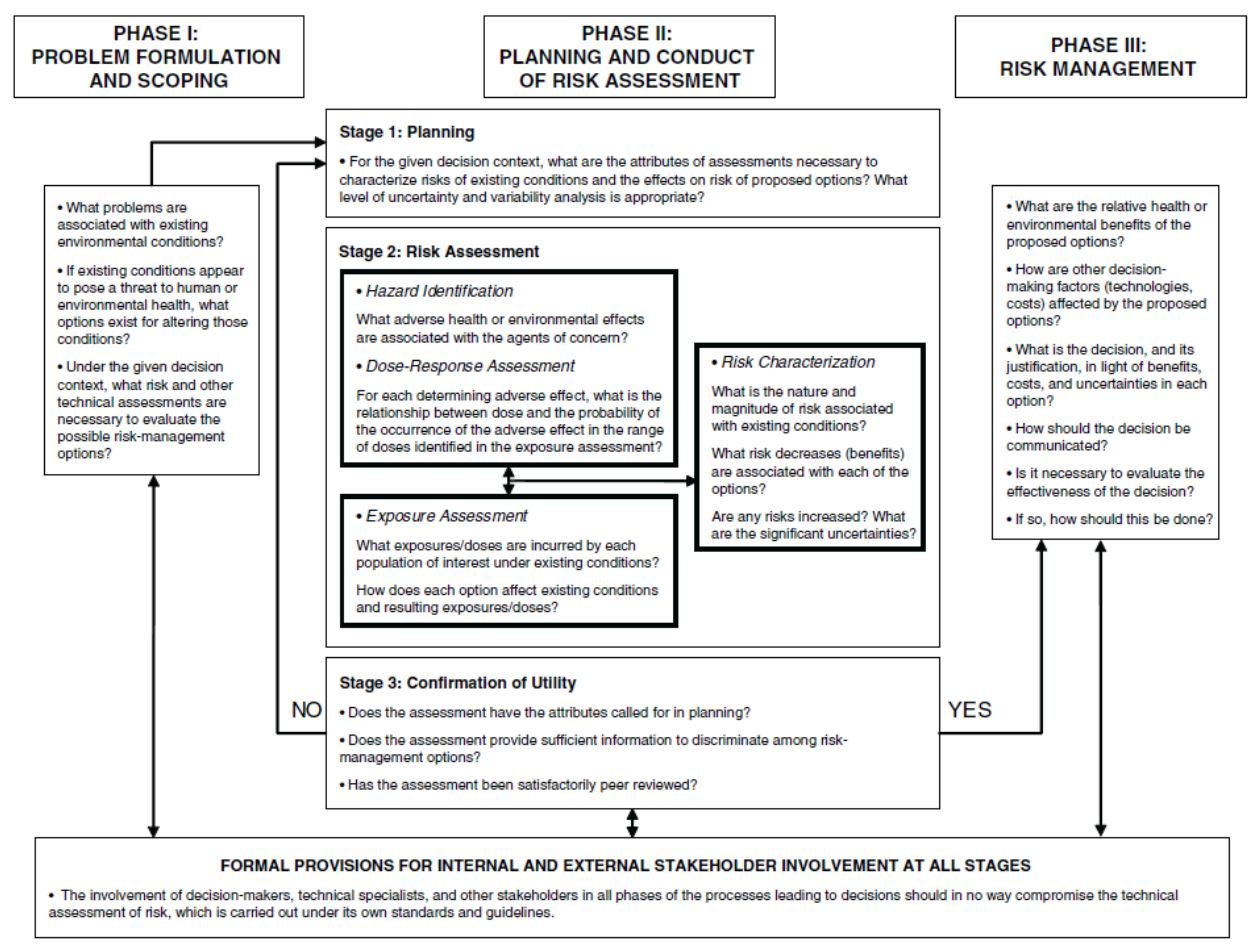


Taken together, movement toward the implementation of the TT21C report creates opportunities for risk assessors and managers to utilise in vitro science as decision making tools within a system that is more closely calibrated to human, not animal, disease pathways and endpoints (Krewski et al., 2014).

This opportunity will require that new methods be applied, and perhaps fine-tuned, by regulators and other decision makers. In the USA (and worldwide), toxicity data is used for making decisions under a variety of laws and regulations by different international, federal, provincial, state and local agencies. Thus, while a methodology and the data it produces might not change, its use and applicability will vary depending upon the regulatory standards to which it is applied and on the agency using it. For example, if a regulatory scheme calls for prioritising a large number of chemicals for future testing, an in vitro screening approach could be appropriate. In contrast, if regulations require that the government or industry demonstrate that a chemical is hazardous, a different approach will be needed that would require more mechanistic and predictive information. The same data might be used in either situation, but for different purposes and with different emphases. Going further, different agencies must implement different laws, often using the same scientific information.

It is very important to understand how these new methods will be deployed in the regulatory system, and be aware of their strengths and limitations within the context of the laws and regulations and the agencies that must apply them. Understanding disease processes and how low/high dose responses challenge cellular networks within a biological system will change dose-response and in vitro to in vivo analysis. A systems biology approach will add to the understanding of which network motifs switch cells from homeostatic to adaptive response and back again, or from adaptive to apoptotic or perturbed response thus increasing the probability of adverse health outcomes (Zhang et al., 2010). A low dose challenge may initiate different pathways compared with a high dose challenge or the same pathways may be changed to different degrees dependent on dose. The new definition of adverse health outcome will be based on probabilities as opposed to extrapolation from a no observable effect level (NOEL) divided by uncertainty factors. New methods of extrapolation and $\mathrm{POD}^{2}$ are discussed in NexGen framework (Krewski et al., 2014).

Many of these challenges were originally outlined in chapter 4 of the TT21C report, and have been updated in recent publications by Andersen et al. (2010) and Krewski et al. (2011). The TT21C vision and strategy proposes a time line that overlaps four phases of important scientific advancements in assay development (Table 1). This approach allows past in vivo knowledge and new in vitro techniques to be compared, and used together to support the continuing application of traditional and new data to risk assessment. This new roadmap, which was discussed in USEPA's strategic plan, integrates the components of chemical screening and prioritisation, toxicity-based pathway risk assessment and institutional transition (USEPA, 2009).

There are two opportunities for which new methodologies and tools should be fast tracked. First, new technologies should be created for pathways and toxicological endpoints for which there are now no, or inadequate, animal-based tests (perhaps developmental neurotoxicology is one such area). Second, new methodologies should be developed for screening large numbers of compounds, where preliminary decisions about further testing are required. Recent publications by Andersen et al. (2010) and Krewski et al. (2011) review many of the new scientific methods that will lay the foundation for toxicity testing in the future. 
The USEPA has launched several key research projects under the USEPA's NCCT dedicated to moving the vision forward and changing the scientific tools used for risk assessment, such as ToxCast, Tox21, ExpoCast, v-Liver, v-Embryo, ACToR, DSSTox, ToxRefDB and iCSS dashboard (USEPA, 2014a). In addition, a new approach has been developed that integrates the use of all types of data including traditional in vivo data and new scientific methods such as high-throughput screening (HTS) in vitro assays and 'omics' microarray information. This weight-of-evidence format for analysing data from different sources is called the toxicological priority index (ToxPi). All data evaluated for a chemical(s) is assigned a score index and a pie chart is generated that ranks the toxicity of the chemical (Reif et al., 2010).

The TT21C vision (2007), the strategic plan (2009) and the NexGen project (Cote et al., 2012) assume that the first phase for in vitro testing high throughput screening is to categorise chemicals into different tiers of toxicity. The first tier of testing would be generalised and contain a battery of tests that analyse all possible conditions of toxicity. The purpose of the first tier would be to rank tens of thousands of substances based on their bioactivity profile (Dix et al., 2007; Firestone et al., 2010; Judson et al., 2010; Krewski et al., 2010). Potentially hazardous substances would then move to the next tiers of testing and undergo a more thorough analysis including animal studies. A major objective of the NexGen project was the development of targeted prototype assessments to help engender movement from strategy to practical application (Cote et al., 2012). The first, second, and third tiered studies have been summarised and linked to current scientific tools and techniques by Krewski et al. (2014). One aspect of tiered testing could include the comparison of similar compounds with similar functions side by side to test for the least hazardous compounds, and direct markets toward a safer product (Anastas and Eghbali, 2010).

Third, these new methods will require validation and regulatory acceptance (Hartung, $2009 \mathrm{~b}, 2010)$. In the USA, the federal government's process for validation and regulatory acceptance falls under the Interagency Coordinating Committee on the Validation of Alternative Methods (ICCVAM) Act of 2000. The ICCVAM act identified the Interagency Coordinating Committee on the Validation of Alternative Methods, housed at the NIH (in the National Institute for Environmental Health Sciences) as the hub for both validation and regulatory acceptance. The 2000 law formally recognised this committee, which had been in operation since 1997. ICCVAM provides a potentially powerful path forward for the validation of promising in vitro testing methods but the progress toward this goal under ICCVAM has been painfully slow and subject to criticism. As of April 2008, ICCVAM had approved tenor fewer in vitro-based alternatives out of almost 200 reviewed over a ten year period. By contrast, the European Centre for the Validation of Alternative Methods (ECVAM) had approved over 30 alternatives, with 170 more under consideration or in line for review (Myers and Locke, 2012). As currently administered the ICCVAM law and the coordinating committee face several important limitations. It lacks adequate staff and independent funding. Under the ICCVAM act, the coordinating committee functions largely in an advisory capacity. Other US federal agencies - including USEPA, FDA and other regulatory agencies - can choose not to accept ICCVAM test recommendations for a variety of reasons under the law. Most troubling, a validated test recommendation can be denied regulatory acceptance on the overly general basis that a test recommendation is unacceptable for satisfactorily fulfilling the test needs for that particular agency and its respective congressional mandate (National Toxicology Program, 2000). All of these 
weaknesses in the ICCVAM law and its process create challenges for both validation and regulatory acceptance of new testing methods and the data they produce.

\subsection{International harmonisation of testing regulations and stakeholder involvement}

Many businesses are multi-national enterprises, and develop and market products worldwide. These businesses can face challenges when laws and regulatory standards about testing requirements are unclear or in conflict. For example, testing on animals of cosmetics or their components has been effectively banned as of March 2013 in the EU member states (EUROPA, 2009). Yet certain nations require that animal-based toxicity tests are completed in order to market a product (Bottini and Hartung, 2009). Thus, a key challenge for the implementation of the TT21C vision and strategy is to determine in which nations animal testing is required, and seek to harmonise laws and regulations transnationally so that at a minimum in vitro toxicity and safety testing is considered. This patchwork of international laws and regulations presents opportunities to demonstrate how non-animal-based toxicity testing is effective in public health protection. At present, the EU member states and the US have different approaches to implementing a TT21C vision and strategy. Going forward, working within the OECD might spark progress in harmonisation.

The OECD has advanced the establishment of standardised testing across national borders. The OECD has 34 member countries (OECD, 2014c), and creates a forum for different countries to express their points of view and come to a consensus on international rules and policies for cooperation and when appropriate can formalise an OECD council act (OECD, 2014b). There are two types of council acts:

1 a council decision that legally binds all OECD member countries

2 a council recommendation that expresses political will.

For example, in the area of toxicity testing, a council act relating to the mutual acceptance of data (MAD) allows chemical testing data generated in an OECD member be accepted in other member and non-member countries. The data under scrutiny must comply with OECD test guidelines and OECD principles of good laboratory practice (GLP). MAD has saved thousands of animals every year and an increasing number of non-OECD economies adhere to MAD (OECD, 2014a).

OECD standardisation of the testing is crucial for the streamlining of toxicity testing on an international level. Non-member countries will then need to decide whether they find the validation acceptable (Liebsch et al., 2011). It has been shown that new testing methods will only be used by companies when all available markets have accepted the new approach. Companies will use traditional approaches until test guidelines have been agreed upon on an international level and all countries have accepted the new tests. For example, in 2002 OECD approved the local lymph-node assay, a test that predicts skin-related allergic responses to topical applications. Although this was the OECD preferred test it was seldom used (Hartung and Rovida, 2009).

Resistance to change is a common theme among different organisations and many new international markets such as China, Brazil and Russia have not necessarily accepted OECD standards. In addition, OECD standards are cumbersome and animal intensive even with MAD recommendations in place. A unique opportunity exists to link with 
similar projects in Europe: Innomed ${ }^{3}$, CORDIS ${ }^{4}$, ICCVAM, COLIPA, and/or the Netherlands Toxicogenomics Centre ${ }^{5}$, could initiate the formation of an international organisation or sub-organisation (within OECD) that tests and validates in vitro tests.

The EU cosmetics directive could drive the acceptance of new methodologies for both governments and industry. The seventh amendment to the EU cosmetic act changed this act into a regulation, which demands immediate acceptance and enforcement by each member state. The EU commission's cosmetics directive is a framework that is phasing out the use of animals to test cosmetic products and ingredients. This ban has applied to finished cosmetic products since September 2004 and to cosmetic ingredients since March 2009. This ban also includes the marketing of any of these products in the European Community if any testing has been done on animals with some exceptions. However, the full implementation of the ban took place in March 2013, regardless of whether alternative testing methods were available and validated (EUROPA, 2009). This regulation is a good example of how to bring all governments and industries together on an international level as selling to large markets will dictate change.

In 2008, the Environmental Law Institute explored USEPA's guidelines and commented on whether these are compatible the 2007 NRC vision. The conclusions drawn from the analysis determined that the implementation of the NRC vision would not require the enactment of new environmental laws. The successful implementation of the NRC vision would only require a change in policy by USEPA in the form of updated or amended guidelines and regulations (Environmental Law Institute, 2008).

The animal welfare community has assembled a multi-national stakeholder consortium called the Human Toxicology Project Consortium. This consortium is represented by the HSUS and its affiliates, the Humane Society Legislative Fund (HSLF) and HSI (Humane Society of the United States et al., 2009) and the mandate of this group is to act as a unifying force to help facilitate the global shift from animal use to an in vitro cellular response pathway paradigm in toxicity risk assessment (Seidle and Stephens, 2009). The current objectives of the Human Toxicology Project Consortium are to:

1 "facilitate the global implementation of the NRC report, by unifying multiple stakeholder

2 promote dialogue, information sharing and establishment of a research and development roadmap

3 lobby for, coordinate and provide resources to support transatlantic efforts necessary to fulfil NRC vision

4 engage in collaborative outreach to legislative, regulatory, corporate, academic and public interest audiences

5 urgently develop a targeted research program to jump-start the transformation" (Humane Society of the United States et al., 2009).

With the focus on proof of concept efforts, this targeted research plan would examine selected prototype compounds and provide examples for their application in a perturbation pathway driven risk/safety assessment (Andersen and Krewski, 2010).

The HSI, in partnership with the Flemish Institute for Technological Research and the Freie Universität Berlin initiated a new project known as AXLR8 (AXLR8, 2014b). Their aim is to coordinate international research, development, and translational activities to advance the '3Rs' concept (replacement, reduction and refinement) (AXLR8, 2014a). 
Several reports have been published summarising research progress (AXLR8, 2014c) and EU researchers have had a prominent role in the global transition to the TT21C vision for the future of toxicity testing.

\section{Summary and conclusions}

These five symposia examined the challenges and opportunities associated with the implementation of the vision and strategy set out in the NAS TT21C report. The symposia discussions are supported by the literature, which demonstrates that toxicity testing needs to drastically change and the transition requires new scientific methodologies that are cost effective, efficient, and use evidence-based toxicology (Hartung, 2009a; Hartung and Rovida, 2009; Locke, 2009). Based on the discussions and materials presented, the following themes emerged.

First, the TT21C vision and strategy are not self-implementing. From the first symposium, it was clear that the stakeholders and communities impacted by the TT21C report have to cooperate to put it into practice. By extension, it is also clear that advocacy will be required so that attention to the TT21C principles are continuously highlighted to regulators and policy makers. Implementing the TT21C vision and strategy will require continued vigilance over the next decade, and perhaps even longer. Even after new in vitro tests are designed, validated and accepted by regulatory agencies, it will be important to keep pressure on governmental agencies to fine tune new tests and utilise them in decision making.

The risk assessment and risk management communities are key audiences for the new toxicology envisioned by the TT21C report. Environmental policy decision making relies on risk assessment and management - science flows through these processes. A key challenge is to make these new toxicological methods risk assessment relevant.

Second, the TT21C vision and strategy indicate that new toxicology techniques are needed. These techniques must fit the characteristics set out in the TT21C report (i.e., high throughput, human cell-based, pathway focused) but we cannot expect a one-for-one substitution for current animal toxicology tests. Nevertheless, it is clear that solely increasing the quality and quantity of non-mammalian tests is necessary but not sufficient for implementation. It will be essential to consider how tiered testing and integrated testing strategies can be deployed so that the data provided to regulators and decision makers is informative. In other words, how can these new testing protocols, centred on pathways of toxicity and in vitro toxicology, form the basis for the public health protective decisions that are demanded by laws and regulations? Not only must we get the science right (e.g., develop relevant and reliable test methods); right science must be followed (e.g., design tests and test batteries that can answer policy relevant questions).

Third, there are a number of scientific gaps that now exist. Currently, it is not known how many biologically significant pathways and perturbations exist, or which ones will be the most important for toxicity testing purposes. To effectively implement the TT21C vision and strategy, resources will have to be devoted to the discovery and elaboration of these pathways and development of relevant and reliable tests that describe and characterise the pathways.

Fourth, evaluating whether new tests are relevant and reliable - validation - and the routine use of these tests by government agencies - regulatory acceptance - are two critical processes that require immediate reform. The present process for validation, set 
out by the ICCVAM act of 2000, is slow, complex and expensive, and has yielded few validated non-animal alternatives. The process for regulatory acceptance, also set out by the ICCVAM act of 2000, gives governmental agencies considerable discretion not to accept a validated test. As a result, the incentive for entering into the validation process is low.

Fifth, while current efforts to reauthorize the TSCA and implementation of the EU's REACH might be useful in supporting progress toward the TT21C strategy and vision, the TT21C report can be implemented under TSCA and FIFRA as currently written. The regulatory structure and policies that underpin these laws would require substantial change, but this can take place without statutory amendments. As a corollary and viewed through a legal lens, it is important to stress that the implementation of the TT21C report is largely a question of US federal administrative law and policy. The key agencies include the USEPA, FDA and NIH. Within these agencies there are two different groups that are crucial to implementation - the program managers and researchers. The researchers are actively developing and evaluating new toxicological methods. The program managers and leaders will be responsible for using these methods for regulatory decision making. The coordination between these two groups cannot be guaranteed and therefore should be solidified. Unless new scientific methods migrate from the laboratory to the program offices, the TT21C vision and strategy might fizzle.

Sixth, the business community has an important and proactive role to play in implementation. There are at least four distinct business sectors - chemical, pharmaceutical, food and cosmetics/personal care - that are, or should be, involved. Each of these sectors faces a slightly different set of challenges and opportunities. In some of the sectors, in vitro toxicology is used routinely (i.e., pharmaceutical) while in others it is utilised less completely. The regulatory environment in the US, Canada and EU member states for each business sector is also different. For example, in the US cosmetic products are not regulated actively by the FDA (a program of industry self-regulation is in place) but chemicals and pharmaceuticals are pervasively regulated.

Finally, international harmonisation of testing methods and cross-border acceptance of new methodologies will hasten the implementation of the vision and strategy set out in TT21C. The OECD could be a useful facilitator and has a proven track record in international harmonisation of toxicity testing. The business community could be a useful ally in pushing for consistent regulations across nations because it has the potential to create a more streamlined pipeline for product acceptance. However, without public support and continued pressure implementation of the TT21C vision and strategy could be stalled. The public demand for bridging the 'toxics information gap' and its interest in assuring population and environmental protection should be a positive force for change. To keep members of the public engaged, it will be essential to adopt a transparent approach to data sharing and analytical tools, and communicate about toxicity testing advances in a way that engages citizens.

\section{References}

Anastas, P. and Eghbali, N. (2010) 'Green chemistry: principles and practice', Chemical Society Reviews, Vol. 39, No. 1, pp.301-312.

Andersen, M.E. and Krewski, D. (2010) 'The vision of toxicity testing in the 21st century: moving from discussion to action', Toxicological Sciences, Vol. 117, No. 1, pp.17-24. 
Andersen, M.E., Al Zoughool, M., Croteau, M., Westphal, M. and Krewski, D. (2010) 'The future of toxicity testing', J Toxicology and Environmental Health B Critical Reviews, Vol. 13, Nos. 2/4, pp.163-196.

AXLR8 (2014a) EU Funded 3Rs Research [online] http://www.axlr8.eu/eu-funded-3rs-research/ (accessed 31 December 2014).

AXLR8 (2014b) Partners [online] http://www.axlr8.eu/partners/ (accessed 19 December 2015).

AXLR8 (2014c) Publications [online] http://www.axlr8.eu/publications/ (accessed 19 December 2015).

Boobis, A.R., Ossendorp, B.C., Banasiak, U., Hamey, P.Y., Sebestyen, I. and Moretto, A. (2008) 'Cumulative risk assessment of pesticide residues in food', Toxicological Letters, Vol. 180, No. 2, pp.137-150.

Bottini, A.A. and Hartung, T. (2009) 'Food for thought ... on the economics of animal testing', ALTEX, Vol. 26, No. 1, pp.3-16.

Cote, I., Anastas, P.T., Birnbaum, L.S., Clark, R.M., Dix, D.J., Edwards, S.W. and Preuss, P.W. (2012) 'Advancing the next generation of health risk assessment', Environmental Health Perspectives, Vol. 120, No. 11, pp.1499-1502.

Dix, D.J., Houck, K.A., Martin, M.T., Richard, A.M., Setzer, R.W. and Kavlock, R.J. (2007) 'The ToxCast program for prioritizing toxicity testing of environmental chemicals', Toxicological Sciences, Vol. 95, No. 1, pp.5-12.

Environmental Law Institute (2008) Implementing Alternatives to Animal Testing Under US Toxics and Pesticide Laws: Can Chemical Regulation in the United States Keep Pace with a Scientific Revolution in Toxicity Testing? [online] https://toxtestingdc.files.wordpress.com/ 2010/06/9-eli_implementing_alternatives_white_paper_v-1_.pdf (accessed 19 December 2015).

EUROPA (2009) EUR-Lex: Regulation (EC) No 1223/2009 of the European Parliament and of the Council of 30 November 2009 on Cosmetic Products (Text with EEA Relevance) [online] http://eur-lex.europa.eu/legal-content/EN/ALL/;ELX SESSIONID=Svh8JFwH4TLrhG1Csbp KkyJDQxvbK3DwQngFJyMBN0jzlrHdyn9J!-849733904?uri=CELEX:32009R1223 (accessed 19 December 2015).

European Chemical Agency (ECHA) (2014) Forum Final Report on the Pilot Project on Intermediates: Reporting Period: December 2012-June 2013 [online] http://echa.europa.eu/ documents/10162/13577/final_report pilot_pr_intermediates_en.pdf (accessed 19 December 2015).

European Chemical Agency (ECHA) (2015) Information on Registered Substances [online] http://echa.europa.eu/regulations/reach/registration/registration-statistics (accessed 19 December 2015).

European Commission (2013) REACH [online] http://ec.europa.eu/growth/sectors/chemicals/ reach/index_en.htm (accessed 19 December 2015).

Firestone, M., Kavlock, R., Zenick, H. and Kramer, M. (2010) 'The U.S. Environmental Protection Agency strategic plan for evaluating the toxicity of chemicals', $J$ Toxicology and Environmental Health B Critical Reviews, Vol. 13, Nos. 2-4, pp.139-162.

Hartung, T. (2009a) 'Current state of the science of toxicity testing', Talk presented at Ottawa Symposium, Ottawa, Ontario, Canada, 29-30 June.

Hartung, T. (2009b) 'Toxicology for the twenty-first century', Nature, Vol. 460, No. 7252, pp.208-212.

Hartung, T. (2010) 'Lessons learned from alternative methods and their validation for a new toxicology in the 21st century', J Toxicol Environ Health B Crit Rev, Vol. 13, Nos. 2/4, pp.277-290.

Hartung, T. and Rovida, C. (2009) 'Chemical regulators have overreached', Nature, Vol. 460, No. 7279 , pp.1080-1081. 
Interagency Coordinating Committee for the Validation of Alternative Methods (ICCVAM) (2000) APPENDIX E: ICCVAM Authorization Act (Public Law 106-545) [online] http://ntp.niehs.nih. gov/iccvam/suppdocs/subguidelines/sg034508/sgappe.pdf (accessed 19 December 2015).

Judson, R.S., Houck, K.A., Kavlock, R.J., Knudsen, T.B., Martin, M.T., Mortensen, H.M., Reif, D.M., Rotroff, D.M., Shah, I., Richard, A.M. and Dix, D.J. (2010) 'In vitro screening of environmental chemicals for targeted testing prioritization: the ToxCast project', Environmental Health Perspectives, Vol. 118, No. 4, pp.485-492.

Krewski, D., Acosta Jr., D., Andersen, M., Anderson, H., Bailar III, J.C., Boekelheide, K., Brent, R., Charnley, G., Cheung, V.G., Green Jr., S., Kelsey, K.T., Kerkvliet, N.I., Li, A.A., McCray, L., Meyer, O., Patterson, R.D., Pennie, W., Scala, R.A., Solomon, G.M., Stephens, M., Yager, J. and Zeise, L. (2010) 'Toxicity testing in the 21 st century: a vision and a strategy', $J$ Toxicology and Environmental Health B Critical Reviews, Vol. 13, Nos. 2/4, pp.51-138.

Krewski, D., Hogan, V., Turner, M.C., Zeman, P.L., McDowell, I., Edwards, N. and Losos, J. (2007) 'An integrated framework for risk management and population health', Human Ecological Risk Assessment, Vol. 13, No. 6, pp.1288-1312.

Krewski, D., Westphal, M., Al-Zoughool, M., Croteau, M.C. and Andersen, M.E. (2011) 'New directions in toxicity testing', Annual Reviews Public Health, Vol. 32, Nos. 2-4, pp.161-178.

Krewski, D., Westphal, M., Andersen, M.E., Paoli, G.M., Chiu, W.A., Al-Zoughool, M., Croteau, M.C., Burgoon, L.D. and Cote, I. (2014) 'A framework for the next generation of risk science', Environmental Health Perspectives, Vol. 122, No. 8, pp.796-805.

Liebsch, M., Grune, B., Seiler, A., Butzke, D., Oelgeschlager, M., Pirow, R., Adler, S., Riebeling, C. and Luch, A. (2011) 'Alternatives to animal testing: current status and future perspectives', Archives of Toxicology, Vol. 85, No. 8,pp.841-858.

Locke, P. (2009) 'International implications of the U.S. National Research Council report on toxicity testing in the 21st century: challenges and opportunities in implementation (purpose of symposium)', Talk presented at Ottawa Symposium, Ottawa, Ontario, Canada, 29-30 June.

Myers, D.B. and Locke, P.A. (2012) 'Modernizing US chemicals laws: how the application of twenty-first century toxicology can help drive legal reform', New York University Environmental Law J, Vol. 20, pp.35-98.

National Research Council (NRC) (1983) Risk Assessment in the Federal Government: Managing the Process, National Academies Press, Washington, DC.

National Research Council (NRC) (1996) Understanding Risk: Informing Decisions in a Democratic Society, National Academies Press, Washington, DC.

National Research Council (NRC) (2006) Toxicity Testing for Assessment of Environmental Agents, National Academies Press, Washington, DC.

National Research Council (NRC) (2007) Toxicity Testing in the 21st Century: A Vision and A Strategy, National Academies Press, Washington, DC.

National Research Council (NRC) (2009) Science and Decisions: Advancing Risk Assessment, National Academies Press, Washington, DC.

National Toxicology Program (2010) Interagency Coordinating Committee on the Validation of Alternative Methods (ICCVAM) [online] http://iccvam.niehs.nih.gov/ (accessed 19 December 2015).

Organisation for Economic Co-operation and Development (OECD) (2014a) Chemical Safety and Biosafety: Mutual Acceptance of Data (MAD) [online] http://www.oecd.org/env/ehs/ mutualacceptanceofdatamad.htm (accessed 19 December 2015).

Organisation for Economic Co-operation and Development (OECD) (2014b) Chemical Safety and Biosafety: OECD Council Acts Related to Chemicals [online] http://www.oecd.org/ chemicalsafety/oecdcouncilactsrelatedtochemicals.htm (accessed 19 December 2015).

Organisation for Economic Co-operation and Development (OECD) (2014c) Members and Partners [online] http://www.oecd.org/about/membersandpartners/\#d.en.194378 (accessed 19 December 2015). 
$\mathrm{ReFaC}$ (2014) ECHA Reports Increase in the Use of Alternatives to Animal Testing [online] $\mathrm{http}: / / \mathrm{www} . r e f a c . e u / m e d i a c e n t r e / r e f a c n e w s /$ echareportsincreaseintheuseofalternativest.aspx (accessed 19 December 2015).

Reif, D., Martin, M., Tan, S., Houck, K., Judson, R., Richard, A., Knudsen, T., Dix, D. and Kavlock, R. (2010) 'Endocrine profiling and prioritization of environmental chemicals using ToxCast data', Environmental Health Perspectives, Vol. 118, No. 12, pp.1714-1720.

Schoeters, G. (2010) 'The REACH perspective towards a new concept of toxicity testing', $J$ Toxicology and Environmental Health B Critical Review, Vol. 13, Nos. 2/4, pp.232-241.

Seidle, T. and Stephens, M.L. (2009) 'Bringing toxicology into the 21st century: a global call to action', Toxicology In Vitro, Vol. 23, No. 8, pp.1576-1579.

Shah, I. and Wambaugh, J. (2010) 'Virtual tissues in toxicology', J Toxicology and Environmental Health B Critical Review, Vol. 13, Nos. 2/4, pp.314-328.

Stephens, M.L. (2010) 'An animal protection perspective on 21st century toxicology', $J$ Toxicology and Environmental Health B Critical Reviews, Vol. 13, Nos. 2/4, pp.291-298.

The Humane Society of the United States; The Humane Society Legislative Fund; Humane Society International (2009) Human Toxicology Project Consortium [online] http://www.thehamner.org/docs/HTOX_flyer_8-21-09.pdf (accessed 19 December 2015).

United States Environmental Protection Agency (USEPA) (2009) The U.S. Environmental Protection Agency's Strategic Plan for Evaluating the Toxicity of Chemicals [online] http://nepis.epa.gov/Exe/ZyNET.exe/P1003351.TXT?ZyActionD=ZyDocument\&Client=EPA $\&$ Index $=2006+$ Thru $+2010 \&$ Docs $=\&$ Query $=\&$ Time $=\&$ EndTime $=\&$ SearchMethod $=1 \&$ TocRes trict $=\mathrm{n} \& \mathrm{Toc}=\&$ TocEntry $=\& Q$ Field $=\& Q$ FieldYear $=\& Q$ FieldMonth $=\& Q$ FieldDay $=\&$ IntQFiel $\mathrm{dOp}=0 \&$ ExtQFieldOp $=0 \&$ XmlQuery $=\&$ File $=\mathrm{D} \% 3 \mathrm{~A} \backslash$ zy files $\backslash$ Index\%20Data $\backslash 06$ thru $10 \backslash$ Txt $\backslash 000$ 00007\P1003351.txt\&User=ANONYMOUS\&Password=anonymous\&SortMethod=h|$\&$ MaximumDocuments $=1 \&$ FuzzyDegree $=0 \&$ ImageQuality $=$ r75g8/r75g8/x150y150g16/i425 $\&$ Display $=\mathrm{p} \mid \mathrm{f} \&$ DefSeekPage $=\mathrm{x} \&$ SearchBack $=$ ZyActionL\&Back $=$ ZyActionS\&BackDesc $=$ Res ults\%20page \&MaximumPages $=1 \& Z y$ Entry $=1 \&$ SeekPage $=x \& Z y P U R L($ accessed 19 December 2015).

United States Environmental Protection Agency (USEPA) (2010) EPA and Other Federal Agencies Collaborate to Improve Chemical Screening [online] http://yosemite.epa.gov/opa/ admpress.nsf/0/571f805f9c4ff71385257765004cdb78?OpenDocument (accessed 19 December 2015).

United States Environmental Protection Agency (USEPA) (2014a) Computational Toxicology Research [online] http://www.epa.gov/ncct/ (accessed 19 December 2015).

United States Environmental Protection Agency (USEPA) (2014b) TSCA Chemical Substance Inventory: Basic Information [online] http://www.epa.gov/oppt/existingchemicals/pubs/ tscainventory/basic.html (accessed 19 December 2015).

Zhang, Q., Bhattacharya, S., Andersen, M.E. and Conolly, R.B. (2010) 'Computational systems biology and dose-response modeling in relation to new directions in toxicity testing', $J$ Toxicol Environ Health B Crit Rev, Vol. 13, Nos. 2-4, pp.253-276.

\section{Notes}

1 'Read across' is a technique that uses data from already tested chemicals for a particular endpoint and applies this data to similar, but untested chemicals.

2 The point of departure, or POD, is the dose-response point that marks the beginning of a low-dose extrapolation. This point can be the lower bound on dose for an estimated incidence or a change in response level from a dose-response model, such as a benchmark dose model, or a NOAEL or LOAEL for an observed incidence, or change in level of response [online] http://ofmpub.epa.gov/sor_internet/registry/termreg/searchandretrieve/glossariesandkeywordli sts/search.do;jsessionid=EPcLl_74tIMegJadjhtsSonxzMvYh9xFugeH0aFth3JMvcJSZ19h!114 5808723). 
3 The sixth framework program InnoMed integrated research project can be considered a pilot project for the innovative medicines initiative (IMI), which aims to improve the drug development process through a series of public-private collaborations for earlier and better prediction of drug safety and efficacy. The IMI is part of the European Commission's proposal for the seventh framework program on research and technological development (http://ec.europa.eu/research/press/2006/pdf/case_study_innomed_en.pdf).

4 FP7 PROJECTS - the seventh framework programme funded European research and technological development from 2007 until 2013 (http://cordis.europa.eu/fp7/home_en.html).

5 http://www.toxicogenomics.nl.

\section{Abbreviations}

COLIPA European Cosmetics Association

EPA US Environmental Protection Agency

FFDCA Federal Food, Drug And Cosmetics Act

FIFRA Federal Insecticide Fungicide and Rodenticide Act

HTS high-throughput screening

ICCVAM Interagency Coordinating Committee for the Validation of Alternative Methods

NRC US National Research Council

OECD Organization for Economic Cooperation and Development

REACH Registration, Evaluation, Authorisation and Restriction of Chemical substances

Tox21 the Tox21 consortium comprised of EPA, NIH, and FDA

TSCA Toxic Substances Control Act

TT21C Toxicity Testing in the 21st Century: a Vision and a Strategy. 